\title{
Systemic effects of carbon dioxide insufflation technique for de-airing in left-sided cardiac surgery
}

\author{
Maya Landenhed, MD, ${ }^{\mathrm{a}}$ Faleh Al-Rashidi, MD, PhD, ${ }^{\mathrm{a}}$ Sten Blomquist, $\mathrm{MD}, \mathrm{PhD},{ }^{\mathrm{b}}$ Peter Höglund, MD, PhD, ${ }^{\mathrm{c}}$ \\ Leif Pierre, EBCP, ${ }^{\mathrm{a}}$ and Bansi Koul, MD, $\mathrm{PhD}^{\mathrm{a}}$
}

Objective: Systemic effects of carbon dioxide $\left(\mathrm{CO}_{2}\right)$ insufflation during left-sided cardiac surgery were evaluated in a prospective randomized study, with regard to acid-base status, gas exchange, cerebral hemodynamics, and red blood cell morphology.

\begin{abstract}
Methods: Twenty patients undergoing elective left-sided cardiac surgery were randomized to de-airing procedure either by $\mathrm{CO}_{2}$ insufflation technique $\left(\mathrm{CO}_{2}\right.$ group, $\left.\mathrm{n}=10\right)$ or by Lund technique without $\mathrm{CO}_{2}$ insufflation (Lund group, $\mathrm{n}=10$ ). Groups underwent assessment of acid-base status by intermittent arterial blood gases and in-line blood gas monitoring. Capnography was used to determine volume of $\mathrm{CO}_{2}$ produced. Cerebral hemodynamics was measured by transcranial Doppler sonography and near-infrared spectroscopy. Red cell morphology from cardiotomy suction and vent tubing was studied by scanning electron microscopy.
\end{abstract}

Results: Patients in the $\mathrm{CO}_{2}$ group consequently developed significantly higher levels of hypercapnia with a concomitant increase in the volume of $\mathrm{CO}_{2}$ produced despite significantly higher oxygenator gas flows compared with the Lund group. Effects on cerebral hemodynamics were observed in the $\mathrm{CO}_{2}$ group with significantly higher blood flow velocities in the middle cerebral artery and higher regional cerebral saturation. Red blood cell damage was observed in the $\mathrm{CO}_{2}$ group by scanning electron microscopy $\left(97 \%\right.$ in $\mathrm{CO}_{2}$ group vs $18 \%$ in Lund group).

Conclusions: Insufflation of $\mathrm{CO}_{2}$ into the cardiothoracic wound cavity during left-sided cardiac surgery can induce hypercapnic acidosis and increased cerebral blood flow and local blood cell damage. These systemic effects should be monitored by in-line capnography and acid-base measurements for early and effective correction by increase in gas flows to the oxygenator. (J Thorac Cardiovasc Surg 2014;147:295-300)

Insufflation of carbon dioxide $\left(\mathrm{CO}_{2}\right)$ into the pericardial cavity during left-sided cardiac surgery can reduce residual intracardiac air and reduce the risk of air embolism. ${ }^{1-3}$ However, reports have described development of hypercapnic acidosis from $\mathrm{CO}_{2}$ insufflation. ${ }^{2,4,5}$ Furthermore, hypercapnia by its vasodilator effect is known to increase cerebral blood flow, ${ }^{6}$ which could contribute to increased risk of cerebral embolism. Our group has previously described a technique for de-airing (Lund technique) of the left heart that does not utilize $\mathrm{CO}_{2}{ }^{7-9}$ In a prior prospective randomized study, ${ }^{9}$ we compared the Lund technique to the $\mathrm{CO}_{2}$ insufflation technique, and observed significantly higher rates of air emboli recorded by transesophageal echocardiography and microembolic signals by transcranial Doppler sonography (TCD) associated with $\mathrm{CO}_{2}$ insufflation. ${ }^{9}$ In this study we evaluated

\footnotetext{
From the Departments of Cardiothoracic Surgery, ${ }^{\mathrm{a}}$ Anesthesia and Intensive Care, ${ }^{\mathrm{b}}$ and the Clinical Research and Competence Center, ${ }^{c}$ Faculty of Medicine, Lund University, Skåne University Hospital, Lund, Sweden.

Disclosures: Authors have nothing to disclose with regard to commercial support.

Received for publication Aug 2, 2012; revisions received Oct 3, 2012; accepted for publication Nov 6, 2012; available ahead of print Dec 14, 2012.

Address for reprints: Maya Landenhed, MD, Department of Cardiothoracic Surgery, Block A, Floor 8, Skåne University Hospital in Lund, 22185 Lund, Sweden (E-mail: maya.landenhed@med.lu.se).

$0022-5223 / \$ 36.00$

Copyright (c) 2014 by The American Association for Thoracic Surgery http://dx.doi.org/10.1016/j.jtcvs.2012.11.010
}

systemic effects of $\mathrm{CO}_{2}$ insufflation with regard to acid-base balance, gas exchange, cerebral hemodynamics, and red blood cell morphology in the previously described prospective sample. ${ }^{9}$

\section{MATERIALS AND METHODS Study Population}

Patients scheduled for elective open aortic surgery were considered for study inclusion as previously described. ${ }^{9}$ Preoperative exclusion criteria were a history of carotid artery disease, chronic obstructive pulmonary disease and emphysema, previous thoracic surgery, and patients who were being considered for left internal thoracic artery harvesting. Intraoperative exclusion criteria were accidental opening of the pleura during sternotomy in the $\mathrm{CO}_{2}$ group, failure to wean from the cardiopulmonary bypass (CPB), and failure to obtain adequate Doppler signals from the middle cerebral arteries. Twenty consecutive patients were randomized to either the Lund de-airing technique (Lund group, $\mathrm{n}=10$ ) or the $\mathrm{CO}_{2}$ insufflation technique $\left(\mathrm{CO}_{2}\right.$ group, $\mathrm{n}=10$ ) during induction of anaesthesia by opening envelopes indicating deairing technique created from a computer generated randomization list. The study was approved by the ethics committee of Lund University, Sweden, and all included patients provided written informed consent. The study protocol was registered with ClinicalTrials.gov (identifier No. NCT00934596).

\section{Operative Management}

Patients were anaesthetized and monitored during surgery using standardized procedures, including intraoperative transesophageal echocardiography. Patients were ventilated using a SERVO-i ventilator (Maquet Inc, Solna, Sweden) equipped with a module for calculation of $\mathrm{CO}_{2}$ minute production (Capnostat, Respironics Novametrix Inc, City, Conn). Surgery was 


$$
\begin{aligned}
& \text { Abbreviations and Acronyms } \\
& \mathrm{CO}_{2}=\text { carbon dioxide } \\
& \mathrm{CPB}=\text { cardiopulmonary bypass } \\
& \mathrm{LV}=\text { left ventricle } \\
& \mathrm{rSO}_{2}=\text { regional cerebral oxygen saturation } \\
& \mathrm{SEM}=\text { scanning electron microscopy } \\
& \mathrm{TCD}=\text { transcranial Doppler sonography }
\end{aligned}
$$

performed using standard surgical technique. CPB was established using a membrane oxygenator (Compact Flow EVO Phiso; Sorin Group, Mirandola, Italy), an arterial filter (Cobe Century; Sorin Group, Mirandola, Italy), and polyvinylchloride tubing (silicone tubing in the pump heads). Roller pumps (Stockert S3; Sorin Group GmbH, Munich, Germany) and a heat exchanger (T3; Sorin Group, Mirandola, Italy) were used in all patients. $\mathrm{CPB}$ was maintained with a nonpulsatile blood flow rate of approximately $2.5 \mathrm{~L} / \mathrm{minute}^{2} \mathrm{~m}^{2}$ at normothermia. During $\mathrm{CPB}$, patients were cooled to $25^{\circ} \mathrm{C}-28^{\circ} \mathrm{C}$ as measured in the urinary bladder or tympanic membrane depending on whether the aortic arch was replaced or not, respectively. Antegrade cold blood cardioplegia was used for myocardial protection and the left ventricle $(\mathrm{LV})$ was vented through the apex in all patients using a $15 \mathrm{~F}$ Polystan LV drainage catheter (Maquet Inc, Solna, Sweden).

\section{The Lund De-Airing Technique}

The Lund de-airing technique has been described by us previously. ${ }^{7-9}$ It comprises induced collapse of both lungs by opening the pleura bilaterally and disconnection of the ventilator before opening the heart to prevent air from entering the pulmonary veins, and a gradually staged cardiac filling and lung ventilation before $\mathrm{CPB}$ weaning, to expel air trapped in the pulmonary veins.

\section{The $\mathrm{CO}_{2}$ Insufflation De-Airing Technique}

In this group the pleural cavities were left intact. During CPB, patients were ventilated with $1 \mathrm{~L} /$ minute, 5 breaths/minute, and positive end expiratory pressure $5 \mathrm{~cm}$ water. Before cannulation for $\mathrm{CPB}, \mathrm{CO}_{2}$ insufflation was initiated with a gas diffuser placed in the cardiothoracic cavity (Cardia Innovation AB, Stockholm, Sweden) according to the manufacturer's instructions as follows. ${ }^{10} \mathrm{CO}_{2}$ flow was set at $10 \mathrm{~L} /$ minute and continued until 10 minutes post-CPB. Following completion of the surgical procedure and closure of the heart, the heart and lungs were passively filled, the heart was massaged, and the left heart de-aired continuously through the LV vent. Full ventilation was then resumed, and the aortic root was de-aired by active suctioning with the LV vent clamped. The aortic crossclamp was released and the LV vent opened again. After good cardiac contractions, the LV preload was gradually increased by reducing the venous return to the CPB circuit, and the de-airing continued through the vent in the LV apex under transesophageal echocardiography monitoring. When no air emboli were observed in the left atrium, LV, and aortic root, the drainage in the LV was reduced and the heart was allowed to eject. De-airing was continued, and when no air emboli were observed in the left side of the heart, the patients were weaned from CPB and the LV vent was clamped in situ.

\section{Monitoring of Arterial Blood Gases and Gas Dynamics}

Arterial blood samples were drawn intermittently every 15 minutes for analysis of blood gases (ABL800 FLEX; Radiometer, Copenhagen, Denmark). Temperature-corrected blood gases were used to facilitate alpha-stat $\mathrm{pH}$ management. In addition, $\mathrm{pH}$ and $\mathrm{CO}_{2}$ partial pressure were continuously monitored from the arterial line using an in-line blood gas monitor (CDI Blood Parameter Monitoring System 500; Terumo Cardiovascular System,
Ann Arbor, Mich). $\mathrm{CO}_{2}$ partial pressure was targeted to 5.5 to $6.5 \mathrm{kPa}$ for both groups and the gas flow in the oxygenator readjusted when $\mathrm{CO}_{2}$ partial pressure diverged from this interval. $\mathrm{CO}_{2}$ concentration at the gas outlet on the oxygenator was measured using a capnograph (IRMA $\mathrm{CO}_{2}$; Phasein $\mathrm{AB}$, Danderyd, Sweden). $\mathrm{CO}_{2}$ minute production $\left(\mathrm{VCO}_{2} \mathrm{~mL} / \mathrm{min}\right)$ from the oxygenator was calculated as gas flow in the oxygenator multiplied by the concentration of $\mathrm{CO}_{2}$ at the oxygenator gas outlet. Total volume of $\mathrm{CO}_{2}$ in the $\mathrm{CO}_{2}$ group was thus the sum of $\mathrm{CO}_{2}$ from dead space ventilation measured in the ventilator and $\mathrm{CO}_{2}$ measured at the oxygenator gas outlet. In the Lund group $\mathrm{CO}_{2}$ minute production was measured at the oxygenator gas outlet only as the ventilator was disconnected during CPB. For clinical comparison an upper cut-off value at 60 minutes of CPB time was chosen for 2 reasons: (1) to retain adequate number of observations in both groups for statistical comparison, and (2) to permit comparison between the groups when all patients are in cooling or early rewarming phase of surgery.

Arterial and mixed venous oxygen content in blood was calculated according to the following formula:

Oxygen content $\mathrm{mL} / \mathrm{L}=$ Haemoglobin $(\mathrm{g} / \mathrm{L}) \times 1.36 \times$ saturation $(\%) /$ $100+0.0031 \times$ oxygen tension $(\mathrm{kPa})$

Oxygen consumption $\left(\mathrm{VO}_{2}\right)$ was calculated according to the following formula:

$\mathrm{VO}_{2} \mathrm{~mL} / \mathrm{min}=$ arteriovenous oxygen content difference $\times$ pump flow $(\mathrm{L} / \mathrm{min}) / 100$

Respiratory quotient (RQ) was calculated according to the formula:

$$
\mathrm{RQ}=\text { volume of } \mathrm{CO}_{2}(\mathrm{~mL} / \mathrm{min}) / \mathrm{VO}_{2}(\mathrm{~mL} / \mathrm{min})
$$

\section{TCD Monitoring}

Middle cerebral arteries of both hemispheres were monitored continuously for mean blood flow velocities using multifrequency TCD sonography (Doppler box; DWL, Singen, Germany) beginning at the start of surgery and continuing up to 10 minutes after weaning of CPB. ${ }^{11}$ The bilateral probes were fixed transtemporally by head brace. The insonation and reference gate depths were between 50 and $60 \mathrm{~mm}$, sample volume $10 \mathrm{~mm}$, power $180 \mathrm{~mW}$, and gain 10 .

\section{Scanning Electron Microscopy (SEM)}

At the conclusion of CPB in patients 4 and 5 from the $\mathrm{CO}_{2}$ group, clot formation was suspected in the cardiotomy suction tubing close to the pump head. However SEM imaging of the PVC tubings from these patients showed no clot formation but varying degrees of damaged red blood cells. Segments of the PVC cardiotomy suction and vent tubings immediately proximal to the respective pump heads were consequently sent for SEM study in the remaining 10 patients from both groups. Two 15-mm long sections from each tubing sample were fixed in $2 \%$ glutaraldehyde in Sorensen buffer at $\mathrm{pH} 7$ for 2 hours. Each tubing segment was then cut in half along the long axis and dehydrated in a series of graded ethanol concentrations until a dry ethanol critical point drying was reached. Each section was mounted on stub, sputtercoated with $20 \mathrm{~nm}$ gold and examined under a Philips 515 scanning electron microscope by 1 expert who was blinded to intervention groups. All images were recorded at the same magnification. Four representative images from each individual, 20 from each group, were thus available for the comparative study. Five images from each group were randomly selected for detailed calculation of the proportion of damaged red blood cells in each image.

\section{Statistical Analysis}

The randomization list was generated using the Plan procedure in SAS version 8.2 (SAS Institute, Cary, NC). Data were analysed using the stat 
and Hmisc packages of R software (R Foundation for Statistical Computing, Vienna, Austria), version 2.6.0. Continuous parameters are unless otherwise stated expressed as median and first and third quartiles. The Wilcoxon signed-rank test was used for group comparisons.

\section{RESULTS}

Patient groups did not differ significantly in major preoperative characteristics (summarized in Table 1). All patients survived the surgical procedure and were discharged from the hospital in good clinical condition. One patient in the $\mathrm{CO}_{2}$ group experienced transient aggravation of a paresis of the right arm that was present preoperatively. One patient from the Lund group experienced mild perioperative stroke on day 2; symptoms regressed by discharge. The median duration of $\mathrm{CPB}$ was 94 minutes in the $\mathrm{CO}_{2}$ group and 117 minutes in the Lund group. One patient in the Lund group was excluded from calculation of $\mathrm{CO}_{2}$ volume and respiratory quotient due to failure to obtain data from the gas outlet on the oxygenator (Table 2).

There was no difference in $\mathrm{CO}_{2}$ partial pressure between groups before institution of $\mathrm{CPB}$ (Figure 1). In the $\mathrm{CO}_{2}$ group, $\mathrm{CO}_{2}$ partial pressure increased significantly at 15- and 30-minute intervals compared with the Lund group. $\mathrm{CO}_{2}$ partial pressure, however, could be kept within the targeted normal levels in the $\mathrm{CO}_{2}$ group at the expense of significant increase in gas flows through the oxygenator at 30-, 45-, and 60-minute time intervals (Figure 1). At 45 minutes the gas flow in the $\mathrm{CO}_{2}$ group was more than twice as high as in the Lund group: $2.20(1.63-3.10)$ versus $0.65(0.60-$ $1.25) \mathrm{L} /$ minute. Similarly, at 60 minutes the gas flow in the $\mathrm{CO}_{2}$ group was 2.65 (1.78-3.38) L/minute compared with the Lund group's $0.80(0.70-1.45) \mathrm{L} /$ minute. There was no difference in arterial blood $\mathrm{pH}$ between groups before initiation of CPB. After initiation of CPB, $\mathrm{pH}$ decreased to significantly lower levels at 15-, 30-, and 45-minute time intervals in the $\mathrm{CO}_{2}$ group (Figure 1). No significant difference in concentration of blood lactate was found between groups. In the $\mathrm{CO}_{2}$ group the highest level of lactate during CPB was 1.1 $\mathrm{mmol} / \mathrm{L}(0.9-1.6)$ at 60 minutes and in the Lund group it was $1.0 \mathrm{mmol} / \mathrm{L}(0.6-1.2)$ at 45 minutes. $\mathrm{CO}_{2}$ volume during $\mathrm{CPB}$ was at all times higher in the $\mathrm{CO}_{2}$ group compared with the Lund group (Figure 1). However, differences in $\mathrm{CO}_{2}$ volume between the groups were statistically significant at 30-, 45 -, and 60-minute intervals only. At 60 minutes $\mathrm{CO}_{2}$ volume peaked in the $\mathrm{CO}_{2}$ group to $198.0(152.0-229.0) \mathrm{mL} /$ minute compared with $69.6(39.2-105.6) \mathrm{mL} /$ minute in the Lund group (Figure 1). In contrast, the amount of $\mathrm{CO}_{2}$ measured from dead space in the ventilator was $4.5(4.0-8.0) \mathrm{mL} / \mathrm{min}$ ute at 15 minutes, $5.0(3.0-6.0) \mathrm{mL} /$ minute at 30 minutes, 5.0 (4.0-6.0) $\mathrm{mL} /$ minute at 45 minutes, and $5.0(3.8-6.5) \mathrm{mL} /$ minute at 60-minute intervals in the $\mathrm{CO}_{2}$ group.

No significant difference in oxygen consumption was found during CPB between the groups (Table 2). Fraction of inspired oxygen administered during $\mathrm{CPB}$ was similar
TABLE 1. Patient characteristics

\begin{tabular}{lccc}
\hline & $\begin{array}{c}\text { CO } \\
(\mathbf{n}=\mathbf{1 0})\end{array}$ & $\begin{array}{c}\text { Lund group } \\
(\mathbf{n}=\mathbf{1 0})\end{array}$ & $\begin{array}{c}\boldsymbol{P} \\
\text { value }\end{array}$ \\
\hline Age (y) & $71(56-78)$ & $70(59-77)$ & .942 \\
Male/female & $5 / 5$ & $5 / 5$ & \\
Body surface area $\left(\mathrm{m}^{2}\right)$ & $2.0(1.76-2.16)$ & $1.85(1.76-2.06)$ & .743 \\
Original surgical procedures & & & \\
$\quad$ Aortic valve replacement & $6(60 \%)$ & $7(70 \%)$ & \\
$\quad$ Aortic valve repair & $3(30 \%)$ & $1(10 \%)$ & \\
$\quad$ Bentall operation & $1(10 \%)$ & $2(20 \%)$ & \\
$\quad$ Aortic arch replacement & $1(10 \%)$ & 0 & \\
Cardiopulmonary bypass & $94(84-154)$ & $117(105-135)$ & .252 \\
$\quad$ time (min) & & & \\
Aortic crossclamp time (min) & $59(52-88)$ & $89(77-108)$ & .074 \\
Postoperative ventilator time (h) & $6(4-7)$ & $6(4-8)$ & .882 \\
Intensive care unit stay $(\mathrm{h})$ & $22(21-24)$ & $21(20-22)$ & .293 \\
\hline Data
\end{tabular}

Data are presented as mean (range) or $\mathrm{n}(\%) . \mathrm{CO}_{2}$, Carbon dioxide.

for both groups at all intervals. In the $\mathrm{CO}_{2}$ group, the respiratory quotient was significantly higher at 30-, 45-, and 60-minute intervals during CPB than in the Lund group (Table 2).

Blood gas values obtained from intermittent sampling of blood from the CPB circuit and the in-line blood gas monitoring showed a common trend. No statistically significant differences in $\mathrm{CO}_{2}$ partial pressure and $\mathrm{pH}$ measurements were observed between the 2 methods at any time interval.

Blood flow velocity measured in the middle cerebral artery during $\mathrm{CPB}$ was higher bilaterally in the $\mathrm{CO}_{2}$ group than in the Lund group (Figure 2). There was a significant increase in velocity in both hemispheres in the $\mathrm{CO}_{2}$ group from 30 minutes on CPB $(P<.01)$ until end of CPB $(P<.001)$ (Figure 2). In the right hemisphere, statistically significant differences were seen after 30 minutes on CPB and onward in the $\mathrm{CO}_{2}$ group. In the left hemisphere these differences were significantly different already at 15 minutes on $\mathrm{CPB}$ and onward. Regional cerebral oxygen saturation $\left(\mathrm{rSO}_{2}\right)$ is presented in absolute values (Figure 2). In the $\mathrm{CO}_{2}$ group significantly higher $\mathrm{rSO}_{2}$ values were

TABLE 2. Calculated oxygen consumption and respiratory quotient

\begin{tabular}{cccc}
\hline Time on CPB (min) & $\begin{array}{c}\mathbf{C O}_{2} \text { group } \\
(\mathbf{n}=\mathbf{1 0})\end{array}$ & $\begin{array}{c}\text { Lund group } \\
(\mathbf{n = 9 )}\end{array}$ & $\boldsymbol{P}$ value \\
\hline Oxygen consumption & $(\mathrm{mL} / \mathrm{min})$ & & \\
15 & $109.8(72.9-134.5)$ & $118.3(77.4-52.6)$ & .912 \\
30 & $115.8(77.0-120.5)$ & $114.9(76.6-139.6)$ & .481 \\
45 & $100.6(84.5-150.9)$ & $109.7(91.4-151.2)$ & .579 \\
60 & $125.9(97.2-137.4)$ & $109.2(101.9-151.5)$ & .905 \\
Respiratory quotient & & & \\
15 & $0.78(0.56-1.01)$ & $0.52(0.39-0.69)$ & .065 \\
30 & $1.01(0.85-1.45)$ & $0.44(0.27-0.59)$ & $<.001$ \\
45 & $1.47(1.29-1.66)$ & $0.45(0.27-0.66)$ & $<.001$ \\
60 & $1.47(1.16-2.36)$ & $0.61(0.49-0.67)$ & $<.001$ \\
\hline Con
\end{tabular}

Continuous variables are presented as median (interquartile range). $C P B$, Cardiopulmonary bypass; $\mathrm{CO}_{2}$, carbon dioxide. 


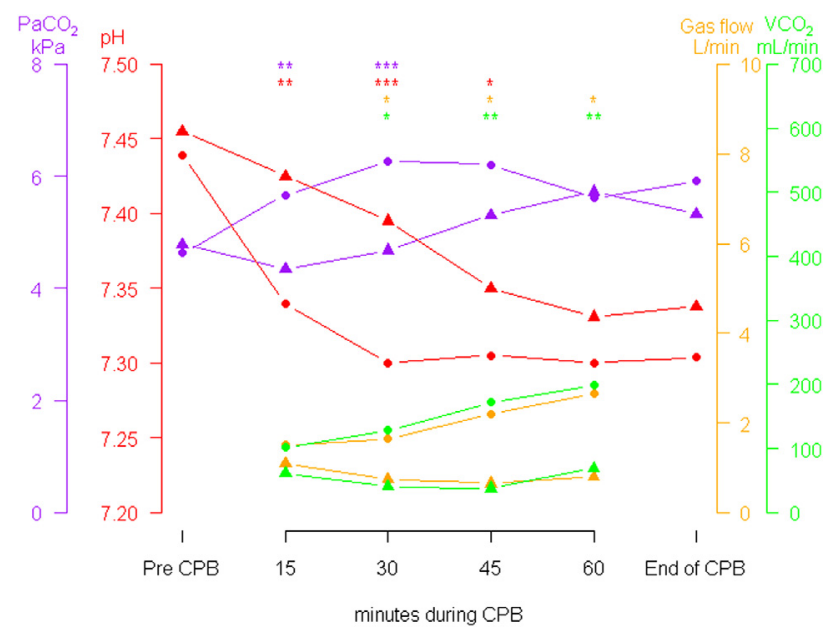

FIGURE 1. Arterial blood gases and extracorporeal gas dynamics before, during, and at the end of cardiopulmonary bypass $(C P B)$. Circles indicate the carbon dioxide group, triangles indicate the Lund group. $\mathrm{PaCO}_{2}$, Partial pressure of carbon dioxide; $\mathrm{VCO}_{2}$, volume of carbon dioxide produced. $* P<.05 ; * * P<.01 ; * * * P<.001$ for between-group comparisons.

recorded from both cerebral hemispheres until CPB was terminated when compared with the Lund group. No statistically significant difference in hematocrit was found between the 2 groups at corresponding time intervals.

The SEM images of the cardiotomy suction and LV vent tubings showed a higher degree of red blood cell damage in the $\mathrm{CO}_{2}$ group (Figure 3). This finding was consistent in the final 5 patients in the $\mathrm{CO}_{2}$ group despite restricted use of

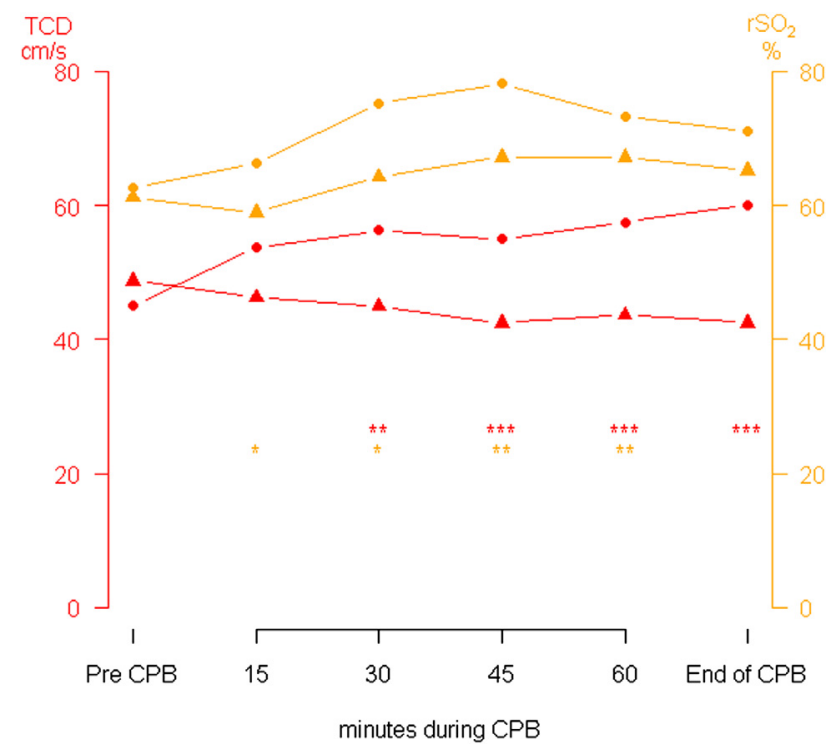

FIGURE 2. Cerebral hemodynamics measured by transcranial Doppler (TCD) and regional cerebral oxygen saturation $\left(\mathrm{rSO}_{2}\right)$ measured by nearinfrared spectroscopy before, during, and at end of cardiopulmonary bypass $(C P B)$. Circles indicate carbon dioxide group, triangles indicate Lund group. ${ }^{*} P<.05 ; * * P<.01 ; * * * P<.001$ for between-group comparisons. cardiotomy suction in this group. The fraction of damaged red cells in the $\mathrm{CO}_{2}$ group was 0.97 (0.64-1.0) compared with $0.18(0.11-0.30)$ in the Lund group. In both the groups the activated clotting times and the heparin concentration was within therapeutic limits throughout CPB.

\section{DISCUSSION}

In our study, $\mathrm{CO}_{2}$ insufflation of the operative field employing a standardized and recommended protocol induced significant hypercapnic acidosis (Figure 1). This occurred despite early and continuous correction by increased gas flow to the oxygenator based on in-line monitoring of blood gases (Figure 1). The increase in $\mathrm{CO}_{2}$ partial pressure corroborates the observed concomitant increase in $\mathrm{CO}_{2}$ volume in the $\mathrm{CO}_{2}$ group (Figure 1), which illustrates the effect of $\mathrm{CO}_{2}$ insufflation on gas dynamics and indicates the necessity to take early and effective compensatory action to avoid acidosis. High arterial partial pressures of $\mathrm{CO}_{2}$ after insufflation of $\mathrm{CO}_{2}$ in the operative field and the necessity of compensational increases in oxygenator gas flows have been described in several previous reports. ${ }^{2,4,5,12}$ During $\mathrm{CO}_{2}$ insufflation, blood from the pericardium returning to the $\mathrm{CPB}$ circuit by cardiotomy suction has a high $\mathrm{CO}_{2}$ content. ${ }^{1}$ Therefore, use of cardiotomy suction in this study was restricted to a minimum. We consistently used a gas diffuser that has been validated previously to provide a sufficient concentration of $\mathrm{CO}_{2}$ in the wound cavity. ${ }^{13}$

The use of a capnograph at the oxygenator gas outlet is a simple adjuvant in controlling appropriate gas flows to avoid adverse effects of $\mathrm{CO}_{2}$ insufflation. ${ }^{12}$ Because the systemic effects of $\mathrm{CO}_{2}$ insufflation seem to rapidly develop, in-line monitoring constitutes an important complement or alternative to conventional intermittent blood gas analysis. Consistent with other reports, ${ }^{12}$ the gas flow through the oxygenator was increased to nearly twice normal to prevent hypercarbic acidosis during $\mathrm{CO}_{2}$ insufflation. There were no differences in oxygen consumption (Table 2) and concentration of lactate between the groups indicating no metabolic component to the acidosis seen in the $\mathrm{CO}_{2}$ group. Also, the contribution of $\mathrm{CO}_{2}$ from the bronchial circulation in the $\mathrm{CO}_{2}$ group during $\mathrm{CPB}$ consisted only of a small fraction of total $\mathrm{CO}_{2}$ volume, indicating that the increased $\mathrm{CO}_{2}$ volume derived from gas insufflation. The CPB time was similar between the groups and the aortic crossclamp time was relatively shorter for the $\mathrm{CO}_{2}$ group (Table 1). The $\mathrm{CO}_{2}$ insufflation was, however, not terminated until 10 minutes after the end of CPB, so the difference in aortic crossclamp time would not have an influence on the difference in $\mathrm{CO}_{2}$ volume between groups.

Cerebral hemodynamics were affected by $\mathrm{CO}_{2}$ insufflation; the mean blood flow velocities in both middle cerebral arteries were significantly higher in the $\mathrm{CO}_{2}$ group than in the Lund group (Figure 2). This observation suggests that the effect of $\mathrm{CO}_{2}$ insufflation on cerebral blood velocity 

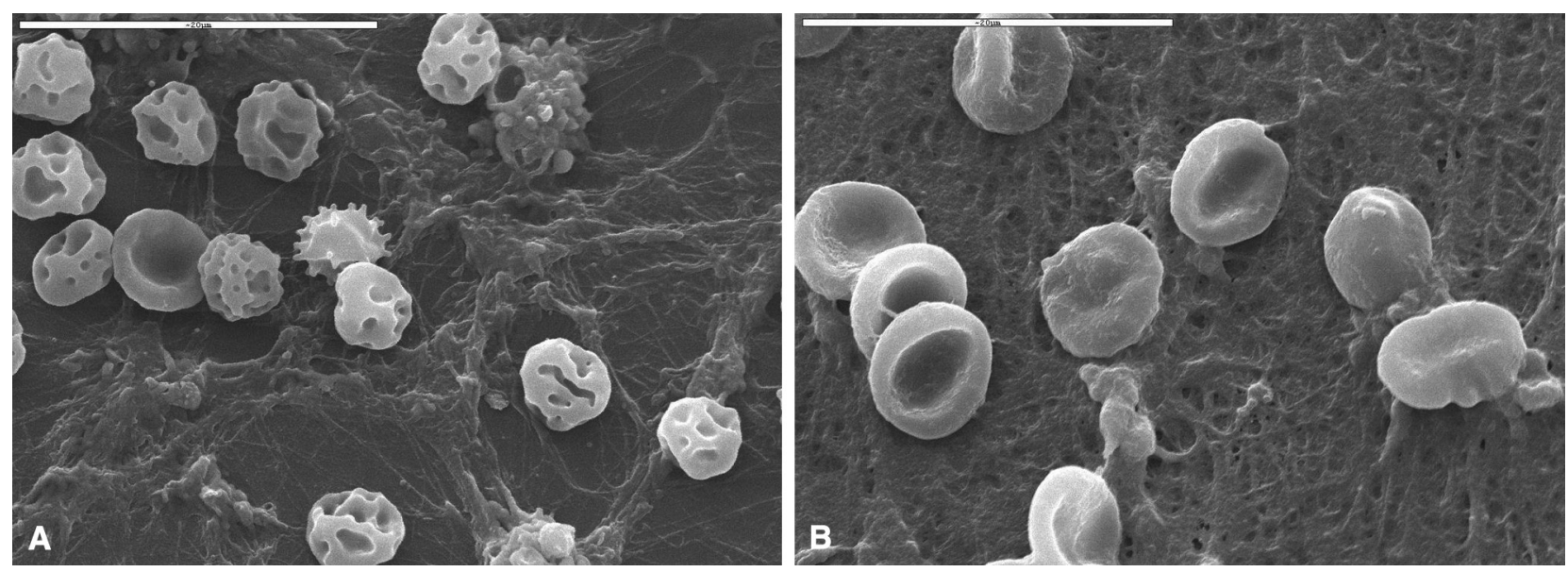

FIGURE 3. A, Scanning electron microscope pictures of the cardiotomy and/or left ventricular vent tubings showing morphology of the red blood cells in the carbon dioxide group. B, Scanning electron microscope pictures of the cardiotomy and/or left ventricular vent tubings showing morphology of the red blood cells in the Lund group. The fraction of damaged red cells in the carbon dioxide group was 0.97 compared with 0.18 in the Lund group.

occurs early and thereafter reaches a plateau because $\mathrm{CO}_{2}$ partial pressure is held within targeted limits by corresponding increases in gas flow to the oxygenator. Increased velocities in the middle cerebral artery as measured by TCD, could theoretically be caused by increased intracranial vascular resistance, or by increased blood flow to the brain secondary to vasodilatation. ${ }^{14}$ In this study $\mathrm{rSO}_{2}$ increased significantly during the entire period of CPB in the $\mathrm{CO}_{2}$ group (Figure 2), suggesting that the increased blood flow velocity in the $\mathrm{CO}_{2}$ group is likely to result from a vasodilator effect of $\mathrm{CO}_{2}$. This is consistent with the general understanding that $\mathrm{CO}_{2}$ has a vasodilating effect. ${ }^{15,16}$ The effect of $\mathrm{CO}_{2}$ insufflation on intracranial pressure was not studied by us because methods to estimate intracranial pressure from blood flow velocity as measured with TCD are based on pulsatile flow and thus not applicable in our study with continuous flow on CPB. In our study, assessment of cerebral blood flow with the TCD technique was not feasible because the diameter of the middle cerebral artery was not known, and probably, variable in size. ${ }^{11}$ Amongst possible methods for investigation of cerebral blood flow is Xenon-133 clearance, by which a correlation of cerebral blood flow to cerebral blood flow velocities has been reported during $\mathrm{CPB},{ }^{17}$ but the relation between velocity and cerebral blood flow is weaker during hypothermic CPB. ${ }^{18,19}$ In a previous report from our group ${ }^{9}$ the amount of microembolic signals was significantly lower with the Lund technique compared with the $\mathrm{CO}_{2}$ technique. However, compared with conventional deairing methods, other groups have described $\mathrm{CO}_{2}$ insufflation technique to be more effective. ${ }^{1,2}$ The rationale for insufflation of $\mathrm{CO}_{2}$ is its greater solubility in blood than air. Injected air emboli have, in animal models, been more detrimental than $\mathrm{CO}_{2} .{ }^{20}$ The finding of altered cerebral hemodynamics in our study raised the concern that the protective effects of $\mathrm{CO}_{2}$ insufflation potentially could be counterbalanced, because a higher number of cerebral emboli, solid or gaseous, could access the cerebral circulation on account of cerebral vasodilatation. The observation that hypocapnia reduced the risk of cerebral embolization during CPB in animal models ${ }^{21}$ could support this theory.

However, in minimally invasive open cardiac procedures, $\mathrm{CO}_{2}$ insufflation may prove to be the better option because manual de-airing is generally not possible. A vent is often used in the pulmonary artery, where the contact of $\mathrm{CO}_{2}$ to blood is minimized. It is unknown if systemic side effects also can be induced by $\mathrm{CO}_{2}$ insufflation used for minimally invasive procedures, but because the wound in minimally invasive procedures is smaller, the corresponding lower flow rates of $\mathrm{CO}_{2}$ insufflation could have the same potential hazards as in conventional surgery.

The finding of a large number of damaged red blood cells in the cardiotomy and vent suction tubing in the $\mathrm{CO}_{2}$ group was not anticipated. This side effect in association with $\mathrm{CO}_{2}$ insufflation has not been reported so far in the English medical literature to the best of our knowledge. From our study it appears that this phenomenon does not seem to affect oxygen consumption in a significant manner in patients undergoing left-sided cardiac surgery with relatively short periods of CPB and aortic crossclamp times (Table 2). However, one should take this statement with caution because our study was relatively small and not primarily aimed at studying this accidental finding in detail.

The patient population in our study was limited. However, the results presented here are consistent in showing that insufflation of $\mathrm{CO}_{2}$ into the cardiothoracic wound during left-sided cardiac surgery can impose systemic side effects that need to be compensated for in the oxygenator. In-line monitoring of $\mathrm{CO}_{2}$ partial pressure is of importance for early and effective compensation actions to prevent the 
development of severe hypercapnic acidosis. The observation of damaged red blood cells from inside the CPB circuit tubing, and its potential clinical effects, needs to be further investigated in a systematic manner in a separate study.

\section{References}

1. Webb WR, Harrison LH Jr, Helmcke FR, Camino-Lopez A, Munfakh NA, Heck HA Jr, et al. Carbon dioxide field flooding minimizes residual intracardiac air after open heart operations. Ann Thorac Surg. 1997;64:1489-91.

2. Kalpokas MV, Nixon IK, Kluger R, Beilby DS, Silbert BS. Carbon dioxide field flooding versus mechanical de-airing during open-heart surgery: a prospective randomized controlled trial. Perfusion. 2003;18:291-4.

3. Svenarud P, Persson M, van der Linden J. Effect of CO2 insufflation on the number and behavior of air microemboli in open heart surgery: a randomized clinical trial. Circulation. 2004;109:1127-32.

4. MacRae WR, Masson AHB, Owen JA, Campbell DG. Carbon dioxide acidosis during open heart surgery. Br J Anaesth. 1964;36:793-7.

5. O'Connor BR, Kussman BD, Park KW. Severe hypercarbia during cardiopulmonary bypass: a complication of $\mathrm{CO} 2$ flooding of the surgical field. Anesth Analg. 1998;86:264-6.

6. Brian JE Jr. Carbon dioxide and the cerebral circulation. Anesthesiology. 1998; 88:1365-86

7. Koul BL, Al-Rashidi F, Roijer A, Meurling C. A new technique to reduce residual air emboli in open left cardiac surgery. J Thorac Cardiovasc Surg. 2009;138:1438-9.

8. Al-Rashidi F, Blomquist S, Hoglund P, Meurling C, Roijer A, Koul B. A new deairing technique that reduces systemic microemboli during open surgery: a prospective controlled study. J Thorac Cardiovasc Surg. 2009;138:157-62.

9. Al-Rashidi F, Landenhed M, Blomquist S, Hoglund P, Karlsson PA, Pierre L, et al. Comparison of the effectiveness and safety of a new de-airing technique with a standardized carbon dioxide insufflation technique in open left heart surgery: a randomized clinical trial. J Thorac Cardiovasc Surg. 2011;141: 1128-33.
10. Persson M, Svenarud P, van der Linden J. What is the optimal device for carbon dioxide deairing of the cardiothoracic wound and how should it be positioned? J Cardiothorac Vasc Anesth. 2004;18:180-4.

11. Lindegaard KF, Lundar T, Wiberg J, Sjoberg D, Aaslid R, Nornes H. Variations in middle cerebral artery blood flow investigated with noninvasive transcranial blood velocity measurements. Stroke. 1987;18:1025-30.

12. Nadolny EM, Svensson LG. Carbon dioxide field flooding techniques for open heart surgery: monitoring and minimizing potential adverse effects. Perfusion. 2000; $15: 151-3$

13. Svenarud P, Persson M, van der Linden J. Intermittent or continuous carbon dioxide insufflation for de-airing of the cardiothoracic wound cavity? An experimental study with a new gas-diffuser. Anesth Analg. 2003;96:321-7.

14. Moppet IK, Mahajan RP. Transcranial Doppler ultrasonography in anesthesia and intensive care. Br J Anesth. 2004;93:710-24.

15. Gibbs FA, Gibbs EL, Lennox WG. Changes in human cerebral blood flow consequent on alterations in blood gases. Am J Physiol. 1935;111:557-63.

16. Kontos HA, Raper AJ, Patterson JL. Analysis of vasoactivity of local pH, PCO2 and bicarbonate on pial vessels. Stroke. 1977;8:358-60.

17. Trivedi UH, Patel RL, Turtle MR, Venn GE, Chambers DJ. Relative changes in cerebral blood flow during cardiac operations using xenon-133 clearance versus transcranial Doppler sonography. Ann Thorac Surg. 1997;63:167-74.

18. Weyland A, Stephan H, Kazmaier S, Weyland W, Schorn B, Grune F, et al. Flow velocity measurements as an index of cerebral blood flow. Validity of transcranial Doppler sonographic monitoring during cardiac surgery. Anesthesiology. 1994; 81:1401-10.

19. Nuttall GA, Cook DJ, Fulgham JR, Oliver WC Jr, Proper JA. The relationship between cerebral blood flow and transcranial Doppler blood flow velocity during hypothermic cardiopulmonary bypass in adults. Anesth Analg. 1996;82:1146-51.

20. Martens S, Theisen A, Balzer JO, Dietrich M, Graubitz K, Scherer M, et al. Improved cerebral protection through replacement of residual intracavital air by carbon dioxide: a porcine model using diffusion-weighted magnetic resonance imaging. J Thorac Cardiovasc Surg. 2004;127:51-6.

21. Cook DJ, Plochl W, Orszulak TA. Effect of temperature and $\mathrm{PaCO} 2$ on cerebral embolization during cardiopulmonary bypass in swine. Ann Thorac Surg. 2000; 69:415-20. 